\title{
ICING - A RISK FACTOR IN AVIATION.CASE STUDY: THE PLANE CRASH IN THE APUSENI MOUNTAINS (ROMANIA) ON 20.01.2014.
}

\section{Şchiopu Cosmin-Liviu ${ }^{1}$, Ionac Nicoleta ${ }^{2}$}

Key words: icing, visibility, weather hazard, the Western (Apuseni) Mts.

\begin{abstract}
Icing - a risk factor in aviation. Case study: The plane crash in the Apuseni Mountains (Romania) on 20.01.2014. Icing is a potentially harmful weather phenomenon for flight safety. Icing, irrespective of its forms, has a negative impact on all aviation activities since it severely impedes the aerodynamic properties of an aircraft, sometimes to such an extent that flying and landing may become impossible. Icing is a serious weather threat to aviation and may ultimately lead to deadly events. One such unfortunate event took place in the Western (Apuseni) Mountains on the 20.01.2014, when an aircraft which was transporting a medical team on a humanitarian mission, simply crashed down in the area of the Western (Apuseni) Mountains, at around 4:00 pm local time. The present study actually makes an inventory of the extremely hazardous flying conditions, by thoroughly analyzing the weather reports and data, as well as visual and synoptic messages or official elements and information from that very day. All these materials show that the flight route and the airdrome of destination were under the influence of a front which accounted for very poor meteorological conditions. On such bad weather, the flight was practically doomed to failure since low snow and sleet-bearing clouds were hanging down over the mountaintops. Flying straight through these clouds made any landmarks impossible to be seen and, furthermore, lack of orientation created false perceptions which led to fatal misjudgements and errors.
\end{abstract}

\section{Introduction}

Description. The icing is an ice deposit, matte or transparent which forms on different parts of an aircraft. Airframe icing can cause a serious loss of aircraft

\footnotetext{
${ }^{1}$ Ph.D. Student, University of Bucharest, schiopulcosmin@yahoo.com

${ }^{2}$ Ph.D. Professor, University of Bucharest, ionac.nicoleta@gmail.com
} 
performance and this will frequently result in a large increase in fuel consumption and some difficulty with aircraft control. Ice will form on an airframe if there is water in liquid state, ambient air temperature below $0^{\circ} \mathrm{C}$, airframe temperature below $0^{\circ} \mathrm{C}$.

Icing can be moderate to severe in clouds formed from supercooled water droplets (a droplet of water still in the liquid state although its temperature is below $0^{\circ} \mathrm{C}$ ). Supercooled water droplets can exist in clouds at very low temperatures and when an aircraft strikes a supercooled water droplet, it will start to freeze. (Ciulache S., Ionac N., 1995).

The effects of icing are important for aviation because ice tends to form on leading ledges, thereby spoiling the aerodynamic shape. The result is reduced lift, increased drag, increased weight, increased stalling speed and increased fuel consumption.

\section{Case study: the plane crash in the apuseni mountains (romania) on 20.01.2014}

On 20 January 2014 a medical team from the National Transplant Agency had to go to Oradea hospital for an organ harvesting. Because it was a medical emergency they decided to use an aircraft from the Romanian Aviation Academy which took off from Baneasa Airport.

The crew which had to go in this humanitarian mission did not have enough time to prepare the flight and it seems that the pilot in command decided to take off without checking the meteorological conditions.

If the crew had been informed about the meterological and synoptic conditions before take off, the pilots would have known that the flight route and the airdrome of destination were under the influence of a front which accounted for very poor meteorological conditions.

\section{Data and methods}

In this study, the following data has been used:

- official reports, information and elements from web sources;

- meteorological data acquired from observations and measurements on 20.01.2014 from Baneasa, Sibiu, Oradea and on the flight route: visual and synoptic messages and airport forecasts;

- meteorological products: synoptical, aerological and icing maps, significant aviation maps, satellite and radar images and radiosounding.

The main methods of research that were used in the analysis, were both visual and instrumental observations, data processing (FM 15-XII Ext, FM 51-XII Ext, FM 12-SYNOP codes), as well as the synoptic interpretation and analysis of maps. 


\section{Weather conditions}

On 20.01.2014, the North-Western part of Romania was influenced by a warm front, which accounted for very poor meteorological conditions covering a large area, including the Western (Apuseni) Mountains.

A vast and active low pressure area from the Mediteranean Sea moved to the centre of Europe, making possible a warm air advection from SW. This active system carried moist air from the Adriatic Sea to the West of Romania. (Fig. 1,2).

This synoptical configuration determined an aggravation of weather conditions especially in the mountains region, since rain, low snow and sleet-bearing clouds were hanging down over the mountain-tops. The cloud systems associated with the warm front, high in moisture, favorized the occurrence of icing inside and above the clouds.

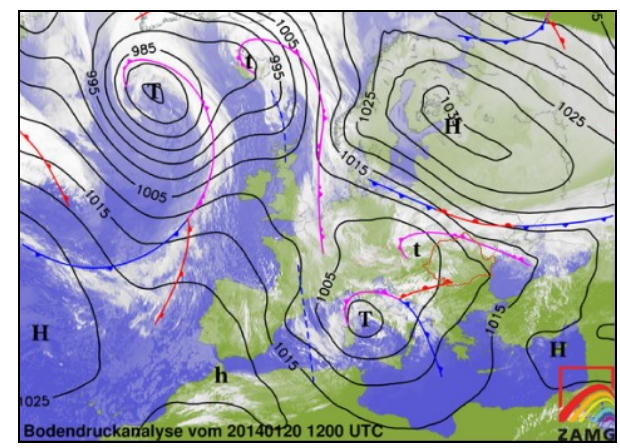

Fig. 1. Surface map 20.01.2014, 12:00 UTC source:http://www.zamg.ac.at

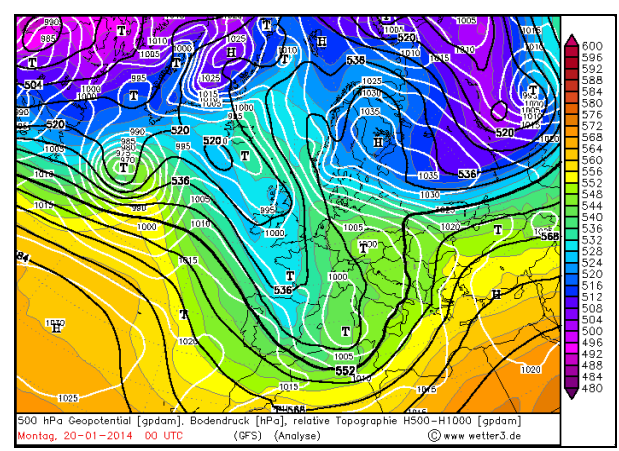

Fig. 2. 500hPa Geopotential, 00:00UTC source:http://www.wetter3.de

\subsection{Weather conditions on the flight route (LRBS-LRSB-LROD)}

The reports emitted by the meteorologist on-duty from the Bucharest-Baneasa airport at 13:00 (LT) for take off: wind from $040^{\circ}$ with 07 knots, horizontal visibility 1,200 m, RVR (Runway Visual Range) 1,600-2,000 m, weather phenomenon: mist, overcast $(8 / 8)$, cloud base $30-90 \mathrm{~m}$, air temperature $6^{\circ} \mathrm{C}$, dew point $5^{\circ} \mathrm{C}$, QNH $1010 \mathrm{hPa}$, temporarly visibility increases to $2,000 \mathrm{~m}$.

\section{$\begin{array}{llllll}\text { METAR LRBS } & 201100 Z & 04007 \mathrm{KT} & 010 \mathrm{~V} 090 & 1200 & \mathrm{R} 07 / \mathrm{P} 2000\end{array}$ R25/1600VP2000N \\ BR FEW001 OVC003 06/05 Q1010 0719//95 TEMPO $2000=$}

The weather conditions on the flight route between 13:00 and 16:00 (LT): cloud coverage: scattered and broken to overcast, visibility 6-10 km, phenomena: 
rain and sleet in the mountains area, wind from NE with 3-5 kt, temperature 6$14^{\circ} \mathrm{C}\left(-2\right.$ to $0^{\circ} \mathrm{C}$ in mountain areas) (Table 1$)$.

Table 2 Weather conditions in the mountain areas

\begin{tabular}{|l|r|c|c|c|c|l|c|}
\hline \multicolumn{1}{|c|}{ LOCATION } & Alt. & T min. $\left({ }^{\mathbf{O}} \mathbf{C}\right)$ & $\mathbf{T}$ max. $\left({ }^{\mathbf{o}} \mathbf{C}\right)$ & $\begin{array}{c}\text { Wind } \\
(\mathbf{m} / \mathbf{s})\end{array}$ & $\begin{array}{c}\text { Precip. } \\
\left(\mathbf{l} / \mathbf{m}^{2}\right)\end{array}$ & \multicolumn{1}{|c|}{ Phenomena } & $\begin{array}{c}\text { Snow } \\
\text { cover }\end{array}$ \\
\hline Iezer & $\mathbf{1 7 8 5}$ & 0 & 3 & $5 / \mathrm{N}$ & 6 & Snow & 11 \\
\hline Vlădeasa Peak & $\mathbf{1 4 0 4}$ & -1 & 1 & - & 2 & Shower rain, sleet, fog & - \\
\hline Paltiniș & $\mathbf{1 4 5 3}$ & 2 & 7 & $3 / \mathrm{SV}$ & & & 16 \\
\hline Bâlea Lac & $\mathbf{2 3 0 7}$ & -2 & 0 & $10 / \mathrm{S}$ & 5 & Snow, fog, drifting snow & 58 \\
\hline
\end{tabular}

In the Sibiu airport approach, the crew recieved the following met report: variable wind with $4 \mathrm{kt}$, visibility $10 \mathrm{~km}$, scaterred clouds (3-4/8), cloud base at $2,000 \mathrm{~m}$, air temperature $13^{\circ} \mathrm{C}$, dew point $6^{\circ} \mathrm{C}, \mathrm{QNH} 1006 \mathrm{hPa}$.

\section{METAR LRSB $201230 Z$ VRB04KT 9999 SCT066 13/06 Q1006=}

For landing airport (Oradea) the following weather conditions were forecasted: visibility 5,000 m, phenomenon: feeble shower rain, cloud coverage: few (1-2/8) to broken (5-7/8), cloud base at 1,000-1,200 m, Cumulonimbus clouds, wind from South with $12 \mathrm{kt}$.

\section{METAR LROD 201430Z 16010KT 9999 -RA SCT039 12/08 Q1005 $0115 / / 95=$ \\ TAF LROD 201100Z 2012/2021 18012KT 9999 SCT040 TEMPO 2016/2021 5000 -SHRA FEW035CB BKN040=}

\subsection{Weather information and data which the crew should have gotten}

Before the take-off, the crew should have recieved the following documents from the meteorologist-on-duty:

1. a satellite image in Visible array (Sat24 South East Europe) and a Radar image from 10:00 UTC;

2. a set of measurements from met stations: Pitesti, Boita, Sibiu, Sebes-Alba, Alba-Iulia, Vladeasa, Oradea containing meteorological data;

3. TAFs (Terminal Airport Forecast) and METARs (Metorological Aerodrome Report) for: Baneasa, Otopeni, Sibiu, Targu-Mures, Cluj-Napoca, Arad and Oradea, from 10:00 UTC;

4. a SIGWX (Significant Weather) SFC/15000 FT AMSL map for the next 6 hours, for Romania, including cloudiness, turbulence and icing forecasts for SFC to FL150 (4.5 km);

5. a SIGWX (Significant Weather) maps for the next 6-12 hours, for Europe, including cloudiness, turbulence and icing forecasts, freezing level for FL100 to FL450 $(13.5 \mathrm{~km})$. These maps were emitted by the WAFA-London; 
6. An Upper Wind and temperature chart for FL005/100 (700hPa) with wind speed, wind direction and temperature at: $150 \mathrm{~m}, 600 \mathrm{~m}, 750 \mathrm{~m}, 900 \mathrm{~m}, 1,500 \mathrm{~m}$ and $3,000 \mathrm{~m}$.

\subsection{Atmospheric conditions in Western (Apuseni) Mountains area (from 15:00 to 17:00)}

In the Western (Apuseni) Mountains area, between 15:00-17:00, the cloud cover was broken (5-7/8) to overcast (8/8) with low (St) and medium (Ns) level clouds, with the cloud base swiftly lowering from initial $150-200 \mathrm{~m}$ to over $60 \mathrm{~m}$. In high mountain areas the low, layer stratus clouds were blending with the fog and mist into one continual atmospheric object, localy the cloud base was so low that it reached the top of the trees (stratus clouds and fog have the same character and structure, the difference is only in the height of their occurrence). The fog, mist and clouds extended from the ground to about 2,000 $\mathrm{m}$ above.

The horizontal visibility between 15:00 and 17:00 was restricted to 2,000$1,000 \mathrm{~m}$ through mist and sleet. The visibility from 16:00 to 17:00 was deteriorating quickly below $1,000 \mathrm{~m}$ as the mist was thickening also because of the sleet. The fog, mist and sleet reduced visibility in the mountain area below $1,000 \mathrm{~m}$.

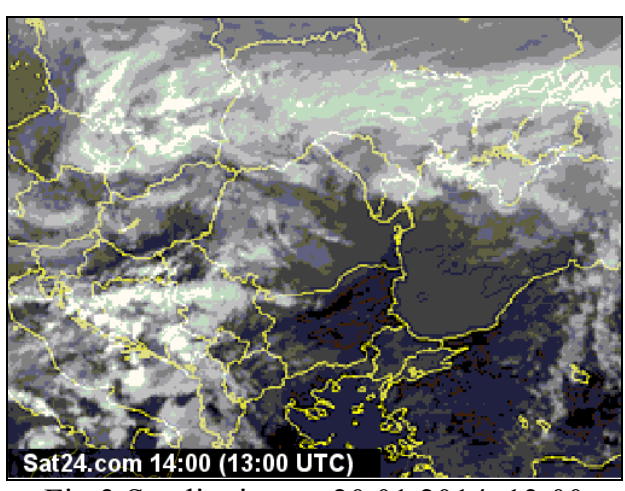

Fig.3 Satelite image 20.01.2014, 13:00

UTC source: http://www.sat24.com

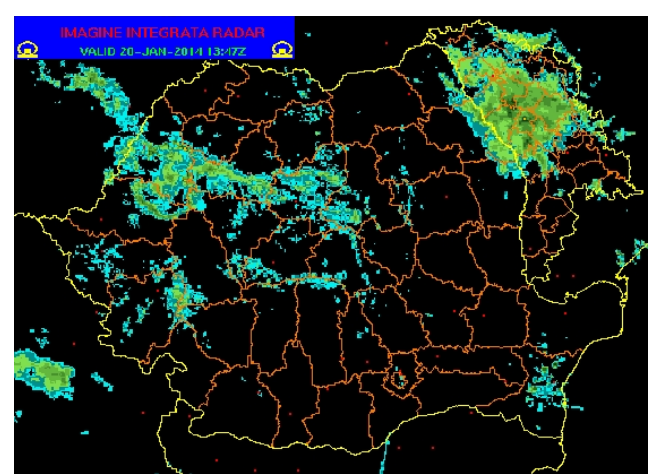

Fig.4 Radar image 20.01.2014, 13.47 UTC source: http:// www.meteoromania.ro/

The presence of Nimbostratus (Fig. 3) and Cumulonimbus clouds (Fig. 4) led to the occurrence of icing. In the cloud systems associated with the warm front, high in moisture, the intensity of icing increased from moderate to severe especialy inside the clouds. 


\subsection{Atmospheric conditions on the place and time of the crash}

At approximate 16:00 (LT), the BN2 aircraft which was conducting a humanitarian flight from Baneasa Airport to Oradea, crashed in the area of Horea village, located at the border of Alba and Cluj counties. As the aircraft passed Sibiu, the crew was instructed by the air traffic control to climb to 090 flight level $(2,700 \mathrm{~m})$. On the meteorological maps, in the Western (Apuseni) Mountains area, there were Nimbostratus and Cumulonimbus clouds high in moisture with a thickness of 2,000-3,000 m favorized the occurrence of icing (Fig. 4). The flight level of the aircraft was crossing a side of the clouds in which the outside temperature was negative, there were supercooled droplets and the airframe icing has diminished the aerodynamic performances of the aircraft, making the flight impossible inside the clouds.

According to the testimonies of the survivors, those of the rescuers and the photos from the crash site, the meteorological conditions at the time of the crash were poor and unfavorable for flight. The cloud base was very low and the clouds were hanging down over the mountain-tops, the horizontal visibility was under 500 $\mathrm{m}$ with fog, low snow and sleet and the melting of snow determined air-humidity to increase in the near-ground air. The misty air, sleet and the low cloud base obstructed the VFR flight (Visual flight rules) and flying straight through these clouds without any landmarks made the emergency landing impossible.

Due to moderate and severe icing, the engines power was reduced and the aircraft descended rapidly and although the crew tried to land, the pilots didn't manage to control the aircraft and they were taken by surprise by the low altitude at which they were flying, the plane struk the trees and crashed in a nearby forest of Horea village in Alba county.

\subsection{Possibilities of forecasting the Ns and Cb clouds and icing conditions}

Although icing is difficult to forecast and needs a full understanding of the processes involved, after a complex analysis, certain areas in which icing conditions are present can be identified. Before take off, the crew can be briefed by meteorologist on-duty about the flight route with a in flight documentation:

- the results of sounding the atmosphere which can help in forecasting the icing by determining the freezing level (Fig. 5);

- icing areas fcst 12-24 HR (Jeppesen) (Fig. 6);

- a SIGWX (Significant Weather) SFC/15000 FT AMSL map for the next $6 \mathrm{~h}$, for Romania, including cloudiness and icing forecasts for SFC to FL150;

a SIGWIX (Significant Weather) maps for the next 6-12 hours, including cloudiness and icing forecasts, freezing level for FL100 to FL450 (Fig. 7). 

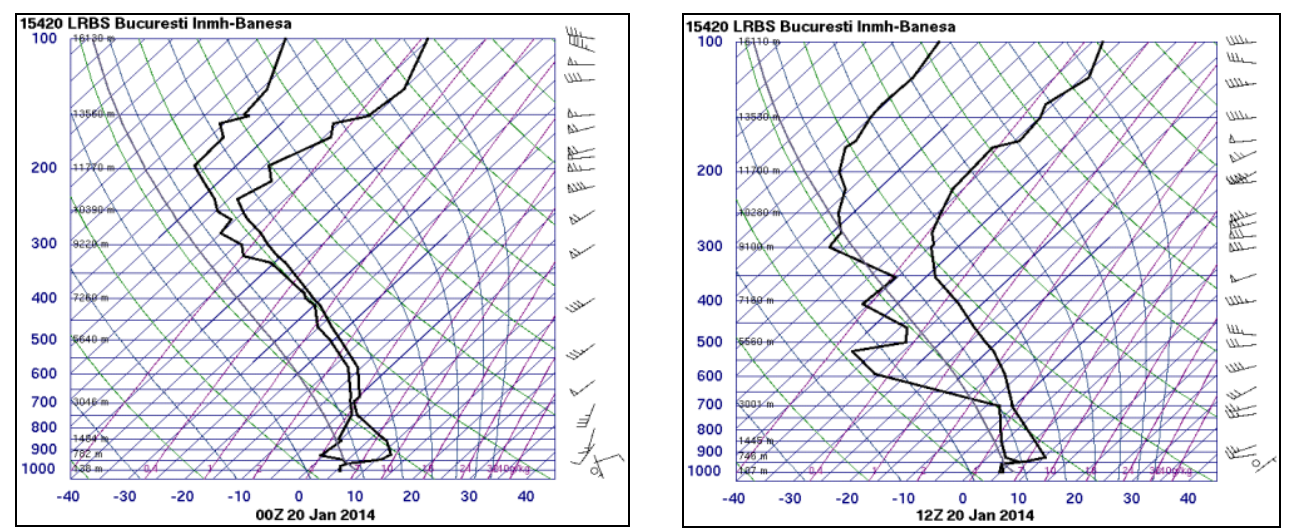

Fig.5 Skew-T diagrams 15420 Bucuresti INMH-Baneasa (radiosounding profile), 20.01.2014, 00:00;12:00 UTC source: http://weather.uwyo.edu/upperair/sounding.htm

The areas with cloudiness can be identified on significant weather charts (high and medium) and are delimited with a scalloped line which shows the demarcation of areas with significant weather. On these charts there are other symbols which refer to precipitation coming into contact with an aircraft, leading to icing at very low temperature and also indicating the low and high limit at which icing can occur (Fig. 7).

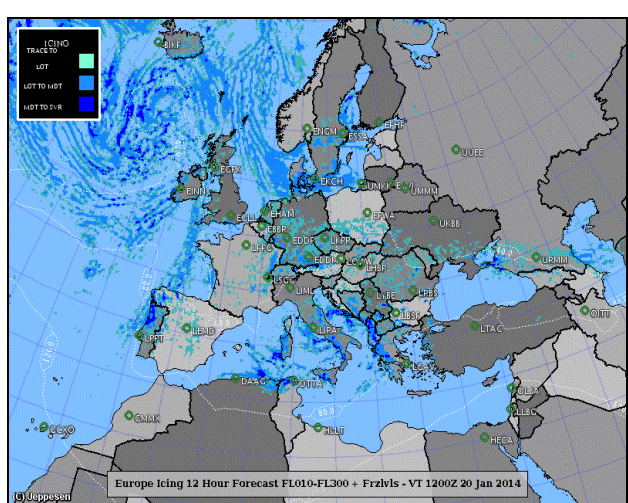

Fig. 6 Icing areas fcst 12-24 HR (Jeppesen) 20.01.2014, 12:00 UTC source: http://euro.wx.propilots.net/

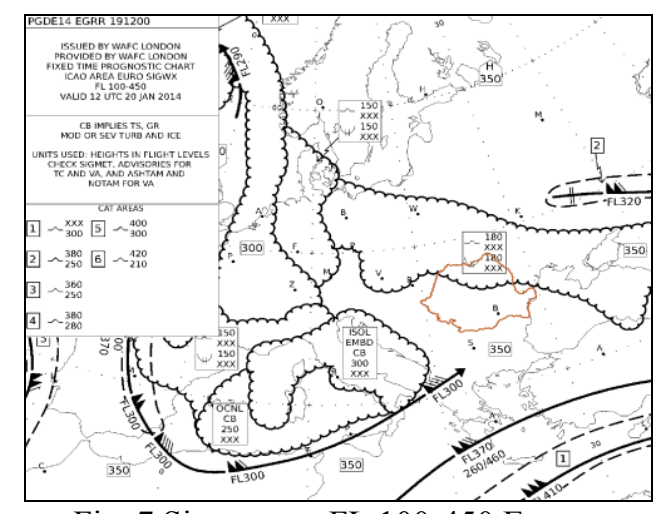

Fig. 7 Sigwx map FL 100-450 Europe 20.01.2014, 12:00 UTC source: WAFC London 


\section{Conclusions} events.

Icing is a serious weather threat to aviation and may ultimately lead to deadly

Flying in icing conditions combined with low visibility is mainly difficult because of the impossibility of orientation after landmarks and pilots may be given a false sense of security.

Icing is a serious threat at take-off, during the flight and landing approach procedure, but also for the ground maneuvers (taxiways). Glazed frost has similar restrictions, but in addition to this, untreated taxiways and runways (deicing and anti-icing) may be covered with a layer of ice, thus amplifying the risks.

A leading factor which caused the accident in the area of the Western (Apuseni) Mountains from 20.01.2014, resulting with two deaths (the pilot and a passanger) and six injuries, were the unfavorable meterological conditions during the flight. (CIAS - Civil Aviation Safety Investigation and Analysis Center).

In the comitee opinion the BN2 airplane engines were functional and the cause of the crash was bad weather and not technical issues.

\section{References}

Ciulache, S., Ionac, Nicoleta (1995), Fenomene atmosferice de risc, Editura Ştiinţifică, Bucureşti, $220 \mathrm{p}$

S. Ciulache (2002), Meterologie și Climatologie, Editura Universitară București, 469p. Gheorghe Ștefan (1991), Meteorologie pentru piloți, Editura Militară, București, 295p.;

Topor, N., Mosoiu,V., Vancea, N. (1967), Meteorologie aeronautică, Ed. Medicala, Bucuresti, 364p.

$* *$ CIAS - Civil Aviation Safety Investigation and Analysis Center (http://www.cias.gov.ro/index.php/en/)

*** http://www.zamg.ac.at

$* * * \mathrm{http}: / /$ www.sat24.com

$* * *$ http:// www.meteoromania.ro/

*** http://weather.uwyo.edu/upperair/sounding.htm

$* * *$ http://ogimet.com/index.phtml.en.

$* * *$ http://euro.wx.propilots.net/

*** http://weather.noaa.gov/fax/wafssig.shtml

*** http://www.wetter3.de/Archiv/archiv dwd.html. 